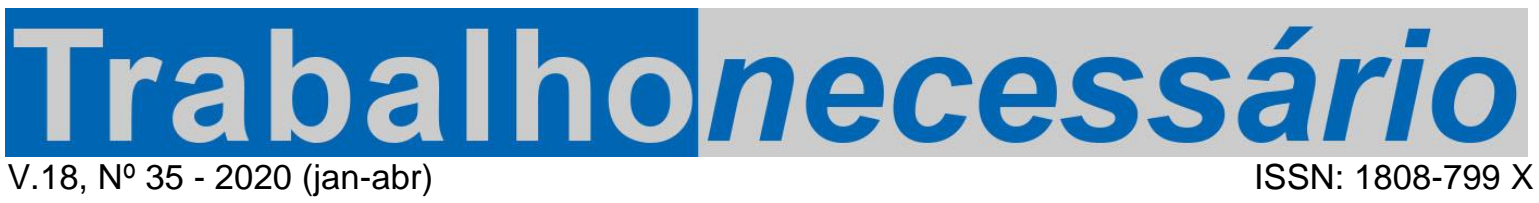

DOI: https://doi.org/10.22409/tn.v18i35.40504

\title{
EDUCAÇÃO DE JOVENS E ADULTOS E EDUCAÇÃO RURAL: CONTRIBUIÇÕES DO MATERIALISMO HISTÓRICO-DIALÉTICO ${ }^{1}$
}

Michelle Freitas Teixeira²

\section{Resumo}

Neste artigo reflete-se sobre as contribuições do materialismo histórico-dialético para pesquisas no campo da educação, a partir do desvelamento das tramas históricas que se fazem presentes na realidade da EJA e da educação rural. Tendo como fundamento a compreensão da história como produção social - como processo real da vida humana em sociedade - desenvolve-se reflexões sobre: as contradições que envolvem a relação entre capital e trabalho; a disputa por diferentes projetos de educação para a classe trabalhadora rural e o caráter histórico da luta por hegemonia no cerne da estrutura do Estado em seu sentido ampliado.

Palavras-chave: Materialismo histórico-dialético. Capitalismo. EJA. Educação Rural.

\section{EDUCACIÓN JUVENIL Y ADULTA Y EDUCACIÓN RURAL: CONTRIBUCIONES DEL MATERIALISMO DIALÉTICO HISTÓRICO}

\section{Resumen}

En este artículo se refleja sobre las contribuciones del materialismo histórico-dialéctico para investigaciones en el campo de la educación, a partir del desvelamiento de las tramas históricas que se hacen presentes en la realidad de la EJA y de la educación rural. Teniendo como fundamento la comprensión de la história como producción social - como un proceso real de la vida humana en sociedad- se desarrollan reflexiones sobre: las contradicciones que envuelven la relación entre capital y trabajo; la disputa por diferentes proyectos de educación para la clase trabajadora rural y el carácter histórico de la lucha por hegemonía en el núcleo de la estructura del Estado en su sentido ampliado.

Palabras clave: Materialismo histórico-dialéctico. Capitalismo. EJA. Educación Rural.

\section{YOUTH AND ADULT EDUCATION AND RURAL EDUCATION: CONTRIBUTIONS OF HISTORIC- DIALETIC MATERIALISM}

\begin{abstract}
This article reflects on the contributions of historical-dialectical materialism to research in the field of education, from the unveiling of the historical plots that are present in the reality of EJA and rural education. Based on the understanding of history as a social production - as a real process of human life in society - we develop reflections on: the contradictions that involve the relationship between capital and labor; the struggle for different education projects for the rural working class, and the historical character of the struggle for hegemony at the heart of the state structure in its expanded sense.
\end{abstract}

1 Artigo recebido em 11/06/2019. Primeira avaliação em 29/18/2019. Segunda avaliação em 01/10/2019. Aprovado em 12/01/2020. Publicado em 23/01/2020.

2 Professora da Área da Educação do Instituto Federal de Educação, Ciência e Tecnologia do Maranhão (IFMA), Doutoranda do Programa de Pós-Graduação em Educação da UFF, membro do Grupo de Pesquisa EJATRAB/UFF. E-mail: michelleteixeira@ifma.edu.br. 
Keywords: Historical-dialectical materialism. Capitalism. EJA. Rural Education. Introdução

Partindo da compreensão da história como produção social da vida humana, como processo no qual são forjadas as condições materiais de sociabilidade, o texto que segue apresenta reflexões sob a perspectiva do método materialista histórico dialético, em torno de algumas categorias que - em diálogo com a tradição marxista - consideramos fundamentais ao desenvolvimento de estudos e pesquisas no campo da EJA e da Educação Rural.

A rigor, inicialmente desenvolve-se algumas reflexões em torno do método materialista histórico-dialético e das contradições que envolvem a relação entre capital e trabalho. Em seguida, tece-se uma análise teórico-metodológica da concepção de Estado, a partir da matriz gramsciana, concebendo-o enquanto Estado Ampliado. Nesta mesma matriz, busca-se perscrutar a categoria hegemonia, compreendida à luz de Gramsci (2011, p. 268) enquanto controle político e cultural de um grupo social sobre toda a sociedade, e a importância deste conceito para o desvelamento das tramas que constituem o consenso e o controle das massas. Destacando-se, neste interim, o entendimento da sociedade civil enquanto terreno no qual se desenvolve a disputa por hegemonia, compreendida como parte fundamental na composição da estrutura do Estado.

Por fim, em linhas gerais, apresenta-se reflexões sobre a EJA e a Educação Rural enquanto modalidades de intervenção que garantem por meio do consenso, 0 controle da classe trabalhadora diante do projeto hegemônico do capitalismo agrário. Sem deixar de considerar no enredo, as disputas e a força da sociedade civil enquanto instância constitutiva do Estado - na conquista de veredas para um projeto contra hegemônico articulado aos interesses da classe trabalhadora.

Partindo da crítica, busca-se desenvolver análises ancoradas em uma chave central: "o concreto é concreto porque é a síntese de muitas determinações, isto é, unidade do diverso" (MARX, 2008, p.260). Logo, parte-se da compreensão da Educação de Jovens e Adultos (EJA) e da Educação Rural como fenômenos históricos e socialmente determinados, compreendendo que as múltiplas determinações se fazem em um processo de disputa cincunscrito no terreno da coerção, do consenso e da luta por hegemonia. Analisamos, a partir deste entendimento, algumas categorias 
que consideramos fundamentais para estudos e pesquisas sobre EJA e Educação Rural.

Antes disso, importa delimitar a nossa concordância com o pensamento de Leher (2018, p. 53), quando este desvela que "estamos num momento da luta de classes mundial em que é absolutamente fundamental retomarmos a preocupação da estratégia". Logo, este trabalho propõe junto às reflexões sobre algumas categorias de análise marxistas, a ampliação do debate destas em articulação com o entendimento das contradições na realidade da EJA e da Educação Rural, historicamente forjadas pelo projeto do capital. Bem como, o levantamento de chaves para a análise coletiva da realidade, a fim de pensar caminhos estratégicos para a orientação tanto das nossas pesquisas, quanto da organização da classe trabalhadora e da luta contra-hegemônica.

\section{Materialismo histórico-dialético, capitalismo e trabalho}

Em tempos de "conhecimentos líquidos" e de valorização, no campo da pesquisa científica em educação, das "pluralidades e diversidades" como que independentes de uma totalidade real, concreta e contraditória, que as determinam que são por estas determinadas, assumimos a - muitas vezes questionada e apontada como ultrapassada - ousadia de ser professora e pesquisadora marxista e de buscar para nosso trabalho docente, estudos e pesquisas, fundamentação nos princípios do materialismo histórico-dialético. Sem com isso adotá-los de maneira acrítica, mas reconhecendo - conforme o próprio método prevê - os limites históricos e dialéticos que nos permitem questionar e movimentar as categorias de análise, compreendendo-as como "instrumentos essenciais à compreensão do real, como abstrações a adquirir concretude e a serem criticamente apropriadas no próprio processo de análise do movimento contraditório do real" (MARX, 2017; RUMMERT, 2000).

Sobre esta perspectiva, Gruppi reflete que o marxismo deve ser concebido como

[...] um processo de construção teórica que acompanha o processo real; é uma crítica contínua do processo real e das teorizações anteriores, portanto critica também a si mesmo, suas próprias formulações e teorizações inadequadas. A não ser assim, transformar- 
se-ia num dogma, numa filosofia especulativa no sentido tradicional e deixaria de ser marxismo (GRUPPI, 1980, p.70)

A ousadia de defender a crítica marxista na atualidade - bem como de apontar os riscos dos reducionismos das investigações científicas no campo da educação e da fragmentação, como analisa Fontes (2005, p.10), "acenada nos nossos dias como a forma final da vida humana" - aparece circunscrita, também, na gravidade deste tempo histórico de avanço da extrema direita no Brasil, com o advento do governo de Bolsonaro "lastreado centralmente em um anticomunismo primário, que considera todas as demais forças sociais diferentes de si mesmo como alvos de sua caça às bruxas" (FONTES, 2019, p.1). Uma realidade historicamente construída, cujas trincheiras de resistência no campo das teorias e dos vínculos destas com o questionamento do real e a organização da classe trabalhadora se fazem urgentes.

Demarca-se como elemento fundamental desta análise, o caráter classista da sociedade brasileira, amparado na condição de desigualdade social e de precariedade das políticas públicas voltadas para a classe trabalhadora, incluindo-se nesta lógica a precariedade da oferta de políticas de EJA. Compreendida, de maneira ampla, como práticas educativas escolares ou não escolares, a EJA caracteriza-se, também, enquanto modalidade de ensino voltada para jovens e adultos que não concluíram os estudos ou não tiveram acesso ao Ensino Fundamental e Médio na idade apropriada. Trata-se, portanto, de uma modalidade, que perpassa todos os níveis da Educação Básica, cuja materialidade encontra-se estreitamente relacionada às contradições que se apresentam no cerne da sociabilidade capitalista.

Logo, reconhece-se a EJA como expressão direta da desigualdade social, que garante à classe trabalhadora ao longo da história, um lugar de permanente precariedade, no que se refere à oferta de políticas educacionais. Condição esta, que revela para estudos e pesquisas no campo da educação, a centralidade do conceito de classe social, tratando-se de uma categoria de análise da realidade, que contribui com o entendimento das desigualdades econômico-sociais na sociedade capitalista, compreendida por Thompson (2018, p. 9) como "um fenômeno histórico, circunscrito nas relações humanas". Portanto, não podemos entender classe a menos que a vejamos como "uma formação social e cultural, surgindo de processos que só podem ser estruturados quando eles mesmos operam durante um considerável período histórico" (THOMPSON, 2018, p.9). Sobre o tema, Badaró Mattos, relembra que 
[...] o conceito de classe social surgiu em Marx e Engels como o centro de sua proposta para a análise das sociedades modernas. O ponto de partida dos autores era uma constatação política de que o proletariado constituía uma nova força política, que acreditavam, teria o papel preponderante na luta pela emancipação (MATTOS, 2012, p. 60)

Logo, o entendimento ao qual se busca articulação para a compreensão da lógica que circunscreve a existência de distintas classes sociais na contemporaneidade, não se situa apenas no reconhecimento da dominação instituída sob a égide do capitalismo, mas, no fato das relações de classe - determinadas em grande medida pelas relações de produção - estarem "diretamente relacionada à consciência de classe, à forma como as relações são tratadas em termos culturais" (THOMPSON, 2018, p. 10). Podendo, portanto, assumir um caráter emancipatório, conforme nos apontam Marx e Engels no conjunto de suas obras.

Trata-se, assim, da constatação da existência de um processo histórico de luta, de disputa - que ocorre, também, no nível cultural - e que por sua vez, não está expressa apenas na correlação de forças entre distintas classes, mas no interior destas. Demarcando o reconhecimento da existência de duas classes fundamentais - a que representa o capital e a que representa os trabalhadores ${ }^{3}$ - sem desconsiderar,

[...] que as mudanças oriundas do processo de desenvolvimento das relações capitalistas, trazem dificuldades para conferir a este conceito sua representação clássica, estando este permeado de questões que emergem da especificidade das relações históricas (RUMMERT, 2000, p 15)

Com isso demarca-se que, investigar a educação de jovens e adultos da classe trabalhadora e a educação rural, sob a perspectiva do materialismo histórico-dialético requer - em diálogo com Kosik (2011, p. 13) - "um détour", um mergulho na materialidade histórica e político-social, que permita alcançar a representação e o "conceito da coisa" em sua essência, inserida num processo de luta por hegemonia. Que, por sua vez, só é passível de compreensão aprofundada a partir de uma análise que considere as condições históricas da formação social e cultural, a totalidade que

\footnotetext{
${ }^{3}$ Referindo-nos à classe trabalhadora, é fundamental o reconhecimento de que as transformações relativas aos novos padrões de acumulação repercutiram de forma intensa na sua constituição no Brasil, a partir de um processo multiforme e contraditório que gerou, de um lado, a fragmentação da classe e, de outro, sua cada vez maior complexificação. Tais alterações, porém, não abalaram as bases seculares de um sistema socioeconômico marcadamente gerador de desigualdades (RUMMERT, 2017, p. 153).
} 
determina a consecução das políticas sociais e as estratégias hegemônicas impostas pela sociabilidade capitalista na reestruturação destas políticas.

Para tanto, neste artigo, parte-se da estreita relação entre a EJA e Educação Rural, considerando a materialidade de sua existência e, nesta, a precariedade das políticas educacionais ofertadas nos territórios rurais brasileiros. Dentre as consequências deste processo, destaca-se no campo brasileiro - em meio a outros problemas - os altos índices de distorção idade-série, imprimindo no campo brasileiro as marcas históricas das contradições educacionais na realidade da classe trabalhadora rural.

Desta forma, considerando a importância do desenvolvimento de estudos e pesquisas que investiguem o problema da EJA no campo, delimita-se como aspecto central da análise que ora se apresenta, a relação entre EJA e Educação Rural, partindo de uma compreensão que considera a existência de um processo de luta por diferentes projetos educacionais, no qual ambas encontram-se inseridas, reconhecendo a luta de classes e a luta por hegemonia enquanto traços importantes de suas histórias.

Como base elementar para o estudo da luta pela hegemonia no campo da EJA e da Educação Rural, demarca-se a importância da história como categoria teórica assentada na compreensão que possui essencialmente uma base terrestre, isto quer dizer que se apoia não na ideia, nem no conceito, mas sim nas classes sociais, nos indivíduos humanos reais, suas ações e condições concretas de vida e existência; “premissa à qual se chega por via empírica, apoiados rigorosamente nas 'lentes' da totalidade dialética" (MARX; ENGELS, 2007, p. 21). Reconhece-se, portanto, que é no processo histórico que se constituem as contradições circunscritas na sua materialidade. Logo, ressalta-se a necessidade de compreensão dos fenômenos sob uma perspectiva de totalidade, buscando a superação da fragmentação do objeto de pesquisa. A fim de evitar reducionismos e conduzir pesquisas comprometidas com

[...] o máximo de honestidade científica, de lealdade intelectual, de ausência de qualquer preconceito e apriorismo ou posição preconcebida, considerando períodos crítico-cronológicos, de modo que se possam estabelecer comparações válidas e não puramente mecânicas ou arbitrárias (GRAMSCI, 2015, p. 18)

Sob este prisma, reconhecendo o caráter histórico e classista da sociabilidade humana, a existência de um permanente processo de disputa por hegemonia, 
apresenta-se como imperativa a necessidade de análise do Estado e das políticas públicas tomando-as enquanto resultado de embate entre frações de classe distintas, em disputa pela inscrição de seus projetos junto "as agências de Estado em seu sentido restrito" (MENDONÇA, 2007, p.16), no cerne das estruturas institucionais que sustentam os governos e suas políticas.

Para tanto, a fim de desvelar a correlação de forças circunscrita por distintos projetos de educação de jovens e adultos trabalhadores do campo ou da cidade, é fundamental demarcar o território político-econômico de análise, cuja materialidade histórico-dialética nos aponta, senão, para as tramas do capitalismo. Logo, para compreender os projetos políticos que ora se propõe perscrutar, é preciso analisá-los imersos nos condicionantes camaleônicos de um sistema que se constitui com base na expropriação da classe trabalhadora e na exploração do seu trabalho para a produção do lucro, seu ponto nodal.

Sendo importante desvelar inicialmente, o caráter essencial do trabalho para a sustentação do capitalismo, cuja produção de riqueza se apresenta estreitamente vinculada à necessidade, acima apontada, de existência de distintas classes sociais subsumidas a uma relação de dominação e exploração, em conformidade com os interesses das diferentes fases produtivas do capital. Tal entendimento foi circunscrito e profundamente analisado por Marx (2017), que nos aponta para o seguinte entendimento:

\begin{abstract}
Abstraindo do valor de uso dos corpos-mercadorias, resta nelas uma única propriedade: a de serem produtos do trabalho. [...] Consideremos agora o resíduo dos produtos do trabalho. Deles não restou mais do que uma mesma objetividade fantasmagórica, uma simples massa amorfa de trabalho humano indiferenciado, de dispêndio de força de trabalho humana, que não leva em conta a forma desse dispêndio. Essas coisas representam apenas o fato de que em sua produção foi despendida força de trabalho humana, foi acumulado trabalho humano. Como cristais dessa substância social que Ihes é comum, elas são valores - valores mercadorias. [...] Assim, um valor de uso ou um bem só possui valor porque nele está objetivado ou materializado o trabalho humano abstrato (p.116)
\end{abstract}

Marx demarca que, sem força de trabalho não há produção de riqueza. Portanto, a expropriação da classe trabalhadora é um fator historicamente imprescindível para a expansão capitalista - seja a expropriação dos meios de produção ou da cultura, cujas contradições geradas por ambas, refletem diretamente na Educação Rural e na EJA, em um duplo aspecto: na expropriação dos meios de 
produção, marcantes nas condições de vida e trabalho da classe trabalhadora rural que detém apenas a força de trabalho como moeda de troca nos sistemas produtivos agrários e, no que se refere à expropriação cultural, na histórica negação de políticas educacionais que visem a ampliação do acesso à escolarização aos trabalhadores rurais.

Desta feita, reconhece-se que a base constitutiva do capitalismo é a existência de trabalhadores "livres" destituídos dos meios de produção e detentores apenas de sua própria força de trabalho. Bem como, destituídos do acesso à escolarização ou conformados por meio de processos educativos mercadologicamente definidos, a uma visão de mundo alcunhada sob os limites dos interesses do capital. Condição esta, que se faz fundamental ao processo histórico de subordinação da classe trabalhadora brasileira, seja ela urbana ou rural, cujas nuances serão analisadas em seguida.

Por hora - seguindo a intenção de "rastrear o nexo interno da matéria desta investigação", conforme observa Marx no posfácio da segunda edição do Livro I do Capital - interessa:

[...] reconhecer a existência de transformações na vida contemporânea, bem como de repensar suas condições de surgimento e sua proximidade ou distância em face de fenômenos já existentes em outras sociedades ou em outros períodos (MARX apud FONTES, 2005, p. 19).

Neste sentido, o reconhecimento da expropriação da classe trabalhadora enquanto um fator essencial para a existência do capitalismo, bem como do caráter marcante deste processo na realidade campesina, nos remete à sua gênese analisada por Marx no capítulo 24, do Livro I do Capital, no qual descreve e analisa o processo de expropriação dos camponeses e a criação do proletariado servil, com o apoio de um aparato jurídico, garantindo condições para a estruturação e implementação do capitalismo. Para este, "a assim chamada acumulação primitiva não é, por conseguinte, mais do que o processo histórico de separação entre produtor e meio de produção, de expropriação" (MARX, 2017, p.786).

Aqui a história nos ampara, nos dá substância para a análise sobre a contemporaneidade, no entendimento do projeto do capitalismo agrário no período de avanço da contrarreforma capitalista neoliberal no Brasil ${ }^{4}$, no qual se destaca o

\footnotetext{
${ }^{4}$ A utilização do conceito "contrarreforma" se deve ao convencimento de que o processo desencadeado a partir dos ajustes do Estado, no caso brasileiro a partir dos anos de 1990, na relação contraditória entre movimentos de restauração e renovação, o primeiro subordinou o segundo. A contrarreforma
} 
acirramento da penetração do capitalismo empresarial nas relações produtivas do campo, alicerçadas na difusão do projeto do agronegócio ${ }^{5}$ e articuladas ao processo de reorganização da sociabilidade do capital - esta última diretamente relacionada ao campo da cultura, afetando a educação rural, afinal, "toda relação de hegemonia é uma relação necessariamente pedagógica" (GRAMSCI, 1987, p.37).

Como consequências desta contrarreforma, amplamente difundida no campo brasileiro, pode-se destacar algumas que nos remetem à permanência do processo de expropriação da classe trabalhadora camponesa, das quais destaca-se: difusão crescente do trabalho assalariado, precarização do emprego rural, expulsão de médios e pequenos produtores do setor, contínuas migrações campo-cidade, aumento da concentração de terra.

Neste contexto de expropriação, os trabalhadores rurais são indubitavelmente reduzidos a força de trabalho disponível para uma inclusão forçada ${ }^{6}$, no projeto produtivo do capital, vinculado ao agronegócio. Sobre este processo - aqui ampliado para a classe trabalhadora urbana e rural - Fontes $(2005$, p.24) destaca o evidenciamento desta inclusão no "processo de mercantilização da vida social e, em grande medida, a mercantilização da força de trabalho, tornando-se o assalariamento sua representação emblemática".

O que por sua vez nos remete à análise de Marx (2017, p.796) sobre a acumulação primitiva - século XIX - quando os capitalistas burgueses transformaram o solo em artigo puramente comercial, ampliaram a superfície da grande exploração agrícola, aumentaram a oferta de proletariados livres, provenientes do campo. Levando-nos, a partir de uma análise crítico-cronológica, ao reconhecimento da perpetuação do processo de expropriação produtiva da classe trabalhadora, enquanto base fundamental para a sustentação do sistema capitalista - condição anteriormente

operada no país teve como pressupostos os princípios liberais eleitos pela agenda organizada a partir dos intelectuais coletivos do capital, entre os quais, o principal deles, ou mais influente nas políticas educacionais no Brasil, foi o Banco Mundial (LAMOSA, 2014, p. 66).

5 O agronegócio é concebido como a personificação das necessidades de reprodução do capitalismo, novo pacto político do conjunto do empresariado brasileiro em torno da definição de novas alternativas para o desenvolvimento (BRUNO, 2019, p. 150).

${ }^{6}$ Recorremos ao conceito da Virgínia Fontes (2005, p.23), quando esta analisa que a generalização da mercantilização da sociedade, componente essencial da expansão capitalista, reduzia (ou simplesmente eliminava) a possibilidade de sobrevivência individual fora do mercado. Neste sentido, a exclusão, historicamente constituída e perpetuada - a impossibilidade de assegurar a subsistência converter-se-ia na impossibilidade prática de escapar a esse processo. Essa inclusão forçada assegurava a própria sobrevivência do sistema, ao submeter e disciplinar a força de trabalho necessária à existência. 
analisada como fundamental na constituição das contradições que permeiam a oferta de políticas de EJA e educação rural, ou a sua negação.

Caminhando em espiral, em busca das condições contemporâneas reconhecese que:

[...] uma vez implantado, em sua "revolução contínua", o capitalismo transforma-se por dentro, absorvendo sempre novas atividades, criando novas necessidades, multiplicando processos de produção, convertendo formas tradicionais em processos industriais, a fim de garantir os domínios do Capital (FONTES, 2005, p. 28).

Neste ponto, retoma-se a análise de Marx, segundo a qual mercadoria é resultado do trabalho humano - logo, é o trabalho que gera valor - destacando que, para a assertividade desta lógica, é imperativo que a classe que produz a riqueza seja mantida sob controle, adequada e subsumida aos interesses e processos que garantem a permanência do lugar da exploração e condições de perpetuação do capitalismo como sistema hegemônico. A classe trabalhadora precisa ser controlada e (con)formada, necessitando para isso da existência de estratégias de coerção e de consenso. Entretanto, a história não se dá sem resistências, sendo a luta por hegemonia um elemento fundamental, ou seja, a luta pelo controle político e cultural.

Mais uma vez, destaca-se nesta trama, a correlação de forças entre distintos projetos de sociedade e de concepção de mundo - que se inscreve no campo da estrutura econômica e política, mas também, no campo da cultura, como demarca e avança Gramsci (2011, p.267) identificando que "o Estado tem e pede o consenso, mas também "educa" este consenso".

Neste interim, cultura e educação se apresentam enquanto instrumentos imprescindíveis para a manutenção da hegemonia histórica do capital. Alia-se a esta análise, a compreensão do "Estado como um equilíbrio da sociedade civil e sociedade política ou hegemonia política e cultural de um grupo social sobre toda a sociedade, como conteúdo ético do Estado" (GRAMSCI, 2017, p. 228). Logo, compreende-se o Estado como espaço de um movimento de disputas, que se inscreve no terreno econômico, político e cultural.

\section{Estado e hegemonia: EJA e educação rural em questão}

Para Lenin (2010, p.27), "o Estado aparece onde e na medida em que os antagonismos de classe não podem objetivamente ser conciliados". E, reciprocamente, a existência do Estado prova que as contradições de classe são 
inconciliáveis. Sendo o processo revolucionário a alternativa para a superação dos dilemas históricos da classe trabalhadora e de sua opressão dentro dos limites do sistema capitalista. Um processo que, como analisa Gruppi (1980, p. 67) acerca do pensamento de Lenin,

[...] não se dá pela quebra imediata do Estado, mas pela sua reorganização, que levará à extinção e que depende de maneira determinante da constituição de uma revolução cultural, isto é, de acesso das grandes massas operárias e camponesas a novos níveis de cultura (GRUPPI, 1980, p. 67).

Gramsci, em seu conceito de Estado - compreendido de maneira mais ampla e orgânica, considerando a análise de Lenin e de outros pensadores marxistas retoma, aprofunda a compreensão da centralidade da cultura e demarca sua importância para o projeto revolucionário, reconhecendo que o processo de conquista e de manutenção da hegemonia depende da elaboração e da difusão de uma concepção de mundo crítica e consciente. Neste sentido,

[...] criar uma nova cultura não significa apenas fazer individualmente descobertas "originais"; significa também, e sobretudo difundir criticamente verdades já descobertas, "socializá-las" por assim dizer; transformá-las, portanto, em base de ações vitais em elemento de coordenação e de ordem intelectual e moral. $O$ fato de que uma multidão de homens seja conduzida pensar coerentemente e de maneira unitária a realidade presente é um fato "filosófico" bem mais importante e "original" do que a descoberta por parte de um "gênio filosófico" de uma nova verdade que permaneça como patrimônio de pequenos grupos intelectuais (GRAMSCI, 1987, p. 13-14).

Trata-se, portanto, diferente da lógica do capital que historicamente estabelece limites ao acesso da classe trabalhadora à cultura e sua perspectiva crítica - na qual EJA e Educação Rural enquanto questões de classe representam de maneira determinante esta condição - da necessidade de difusão de conhecimentos aliados ao projeto socialista de emancipação da classe trabalhadora, "de criticar a sua própria concepção de mundo, tornando-a coerente e elevada até o ponto atingido pelo pensamento mundial mais desenvolvido" (GRAMSCI, 1987, p. 12), de recrudescimento da luta pela hegemonia, também, no campo da cultura. Um processo que, em Gramsci, se dá por dentro da própria estrutura do Estado, buscando superar o entendimento deste, enquanto expressão da segmentação entre base e superestrutura. Com isso, avançando para a compreensão do Estado enquanto uma 
articulação entre sociedade civil e sociedade política, síntese das relações sociais historicamente determinadas.

Entretanto, a atuação por dentro da estrutura do Estado não significa a adequação aos "pilares" do capital, o abandono dos princípios da resistência fundamentais ao projeto socialista, o enfraquecimento das bases e a abertura dos projetos da classe trabalhadora às facetas sedutoras do capital em suas versões democrático-burguesas. Não se trata, portanto, de adotar estratégias de corrigir algum detalhe defeituoso da ordem estabelecida, "de forma que sejam mantidas intactas as determinações estruturais fundamentais da sociedade como um todo, considerando que as determinações fundamentais do sistema do capital são incorrigíveis", como adverte Mészáros (2007, p. 197). Não se trata de uma estratégia reformista, mas revolucionária, "que no curso do seu desenvolvimento se rompa, de modo mais radical, com as ideias tradicionais" (MARX; ENGELS, 2010, p. 57).

Neste sentido, em Gramsci (2017, p.248), "na noção geral de Estado entram elementos que devem ser remetidos à noção de sociedade civil (Estado = sociedade política + sociedade civil, isto é, hegemonia couraçada de coerção)", compreendida enquanto um conceito que remete ao entendimento de uma estrutura que deverá ser tomada como um espaço de recrudescimento das resistências populares e não como um espaço de adequação consentida aos ditames hegemônicos, a fim de manter em funcionamento políticas e projetos - abandonando para isso os fundamentos e as estratégias articuladas aos interesses da classe trabalhadora.

Sob a lógica gramsciana, por Estado deve-se entender além do aparelho de governo, também os aparelhos "privados" de hegemonia ou sociedade civil, reconhecendo-o, conceitual e materialmente, enquanto um território político de disputa de classe. Logo:

Compreender o Estado em seu sentido ampliado, não somente nos permite evitar as armadilhas do conhecimento reificado e simplificador, como estimula a desnaturalização dos mecanismos mais profundos de seu funcionamento, não fosse ele uma permanente reconstrução (MENDONÇA, 2007, p. 17).

Ressalta-se, nesse interim, que o Estado não se limita à função coercitiva, mas atua diretamente do campo do consenso para a conquista e manutenção da hegemonia. Destacando-se a importância da Sociedade Civil, cuja representação se dá a partir da composição dos aparelhos privados de hegemonia (APHs), vinculados 
aos interesses das distintas classes sociais e compreendidos na acepção gramsciana, enquanto espaços de organização das vontades e ações coletivas, nos quais a adesão ocorre de maneira voluntária.

Sob esta lógica, demarca-se que a correlação de forças que permeia a estrutura analisada, deriva das condições sociais objetivas, das contradições das quais emergem os grupos sociais (também denominados na teoria gramsciana de frações de classe). Reconhecendo neste contexto, a educação - como sistema de socialização e de aquisição de conhecimentos, entendida como um APH - "enquanto objeto de disputa do Estado, representando as classes sociais hegemônicas ou sendo pressionada pelas demais classes, os setores contra hegemônicos" (CIAVATTA, 2015, p. 24)

A fim de cumprir a missão de garantia do "consentimento ativo dos governados" - como aponta Gramsci (1999, p. 32) - no que se refere às condições objetivas da oferta de educação à classe trabalhadora, destaca-se o caráter imperativo de adequação das políticas educacionais às condições necessárias para a reprodução do capital, garantindo a ampliação da acumulação do capital, também, a partir da (con)formação da "força de trabalho que produz valor" - Marx (2017). Neste sentido, apresentadas como novos projetos:

[...] as políticas de formação da classe trabalhadora, expressam antigas disputas no cenário da educação brasileira, devendo ser compreendidas como rearranjos de uma mesma lógica que gera, ao longo da história, um conjunto de propostas precárias e descontínuas que visa atender prioritariamente às necessidades do capitalismo (RUMMERT, 2017, p. 151)

Desse modo, para o estudo sobre EJA e educação rural é fundamental a compreensão da cultura e educação como instrumentos imprescindíveis para o controle político e cultural do grupo social representativo dos interesses do capitalismo sobre toda a sociedade, bem como para o fortalecimento do projeto contra hegemônico da classe trabalhadora. Conforme Gramsci,

[...] o que de mais sensato e concreto se pode dizer a propósito do Estado ético e de cultura é o seguinte: todo Estado é ético, na medida em que uma de suas funções mais importantes é elevar a grande massa da população a um determinado nível cultural e moral, nível (ou tipo) que corresponde às necessidades de desenvolvimento das forças produtivas e, portanto, aos interesses das classes dominantes. A escola como função educativa positiva e os tribunais como função educativa repressiva e negativa são as atividades mais importantes 
neste sentido: mas, na realidade, para este fim tende uma multiplicidade de outras iniciativas e atividades chamadas privadas, que formam o aparelho da hegemonia política e cultural das classes dominantes (GRAMSCI, 2011, p. 270).

Com base na compreensão ampliada do Estado - e na noção gramsciana de Estado ético ou de cultura - entende-se que a hegemonia capitalista não é natural e imutável, mas, política, coercitiva, histórica e culturalmente determinada. Sob esta perspectiva, as relações capitalistas são resultado da ação humana e, considerando o caráter dialético da história, estas são possíveis de serem superadas, também, pela ação humana - sendo cultura e educação fatores essenciais no processo de resistência e conquista da hegemonia do Estado para o projeto ético pela classe trabalhadora. Portanto, temos como horizonte a tarefa de difusão de uma concepção de mundo crítica, consciente e articulada aos interesses dos trabalhadores, uma tarefa árdua e imprescindível à organização da classe e dos APHs articulados aos interesses desta.

No que se refere ao processo de reprodução do capital, inúmeras são as estratégias para intervir pedagogicamente na (con)formação da força de trabalho. Sendo a EJA um terreno historicamente fértil, cujas tramas encontram-se diretamente relacionadas ao processo de expropriação desta classe, sob a perspectiva de destituição estrutural de direitos que, por sua vez, leva à negação das condições de acesso e permanência nos espaços formais de escolarização. Neste sentido, conforme analisado anteriormente, o capital se fundamenta e se estrutura por diversas formas de expropriação, "entre elas, a negação da autonomia da classe trabalhadora, cuja subsunção a esse processo constitui condição para a sua permanente produção e reprodução" (RUMMERT, 2017, p. 152).

Em vista disso, nos parece importante - à luz do materialismo histórico-dialético - que estudos, pesquisas, bem como a elaboração de projetos educacionais articulados aos interesses da classe trabalhadora, partam de uma compreensão fundamental: educação de jovens e adultos e questão agrária são questões de classe, historicamente forjadas e circunscritas no cerne das contradições geradas pelo processo de expropriação e exploração da classe que produz valor pelo capital.

Bem como, se faz imperativa a necessidade de reconhecimento do trabalho enquanto categoria central, compreendendo que esta centralidade se traduz em movimentos contraditórios: de um lado, atividade humana que produz valor e que, 
subsumida aos interesses de reprodução do capital, é inserida num processo de exploração que destitui as condições de vida e, de outro, como afirma Marx (2017, p. 120), "atividade que produz condições para a existência da vida, a partir da eterna necessidade de mediação do metabolismo entre homem e natureza, portanto, da vida humana".

Trazendo a análise do processo de exploração do trabalho pelo capital, para a especificidade da condição da classe trabalhadora camponesa, destaca-se a “urbanização incessante e o consequente 'esvaziamento' das regiões rurais, que vem reduzindo drasticamente as condições de produção não mercantil da subsistência para a grande maioria da população" (FONTES 2005, p. 25). Ladeada à precarização da condição de trabalho e subsistência, evidencia-se a precariedade da realidade educacional rural, cujos impactos históricos da política capitalista podem ser identificados a partir dos dados estatísticos, nos quais o problema da EJA é amplamente refletido - dentre outros problemas - nas condições de analfabetismo dos trabalhadores rurais.

Embora neste artigo, seja destacado o problema do analfabetismo, da fase inicial da educação formal, compreende-se que este não circunscreve, nem limita a EJA, mas, é aqui apresentado por caracterizar-se enquanto um problema que gerou intensa movimentação social nos anos de 1990, considerando os altos índices apresentados nos territórios rurais. Portanto, interessa reforçar que a EJA em sua concepção ampla, nos remete a práticas pedagógicas escolares ou não, podendo perpassar todos os níveis de ensino da Educação Básica. Logo, a atenção dada a este problema, se refere ao foco da presente análise, que busca problematizar a luta por hegemonia por meio de projetos populares de educação, intensificada no campo brasileiro nos anos de 1990, diante dos índices que se apresentavam - como será analisado posteriormente.

Desta feita, destaca-se que no período de avanço do capitalismo empresarial nas relações produtivas do campo, alicerçadas na difusão do projeto do agronegócio no Brasil, os dados do Instituto Brasileiro de Geografia e Estatística (IBGE/1995) apontavam que $32,7 \%$ da população acima de 15 anos do meio rural era analfabeta. Observando as desigualdades regionais, o Nordeste brasileiro entra em destaque com maior taxa de analfabetismo do País, com um contingente de quase oito milhões de analfabetos, o que corresponde a $50 \%$ do total do País. Esta região apresentava no 
ano de 1996 - período de forte ofensiva neoliberal - uma taxa de analfabetismo de 28,7\% entre a população de 15 anos ou mais anos de (BRASIL. INEP/MEC, 2003). Sendo esta, a condição real que se apresentava, quando da implementação dos primeiros projetos de EJA voltados para a educação de trabalhadores rurais assentados das áreas de reforma agrária, desenvolvidos a partir de articulações entre os Movimentos Sociais, as Universidades e o Programa Nacional de Educação na Reforma Agrária (PRONERA).

Reconhece-se que, nacionalmente, o PRONERA guarda estreita relação com o processo de mobilização popular em torno da construção do projeto da Educação do Campo no Brasil ${ }^{7}$, cuja pauta principal - aliada à luta pela Reforma Agrária - se estabelece em torno da necessidade de conquista de uma política pública de educação que dialogue diretamente com as demandas educacionais reais do campesinato, com a história, o trabalho e a cultura da classe trabalhadora camponesa. No contexto de sua implementação - ano de 1998 - identifica-se que os primeiros projetos executados por meio da articulação entre Movimentos Sociais, Universidades e PRONERA estiveram voltados para a ampliação do processo de alfabetização de trabalhadores rurais assentados da reforma agrária, considerando a materialidade das condições vigentes à época.

Interessa destacar, que tais dados refletem uma realidade historicamente constituída, cuja análise sob a orientação do materialismo histórico-dialético nos apresenta o desafio de superação das estratégias alicerçadas no presente, sem considerar o processo histórico ou sem vislumbrar as perspectivas de transformação revolucionária das condições vigentes.

Neste cenário, entende-se em diálogo com Rummert (2013, p. 417), que as políticas de Educação Rural e EJA são marcadas pelo "controle social e pela lógica de formação para o consenso, a partir imposição de um padrão cultural que nega o valor da experiência da classe trabalhadora". E que, além disso, busca subsumir a EJA à doutrinação empresarial, ao aprisionamento de mentes e corpos num sistema de formação de "capital humano", que "empreende" a capacidade histórica da utopia e de todas as dimensões sensíveis, crítica e criativas do homem em sua

\footnotetext{
${ }^{7} \mathrm{O}$ tema será aprofundado em seguida.

8 Teoria do Capital Humano, base importante para a reprodução do capitalismo, fortalecida nos anos de 1960 atendendo aos imperativos das novas formas que assumem as relações intercapitalistas - ver Frigotto (2010).
} 
omnilateralidade $^{9}$, a fim de (con)formar jovens e adultos para o trabalho aprisionado em sistemas trabalhistas e previdenciários análogos à escravidão.

Uma formação que, aliada à expansão da reforma produtiva capitalista sob orientação dos interesses do agronegócio no campo, delega à educação rural tanto a função de instrumento formador de uma mão-de-obra disciplinada para o trabalho assalariado rural, quanto de consumidores de produtos gerados pelas novas demandas apresentadas pela produção rural (ideológicos e produtivos - incluindo os insumos agrícolas), tendo como mote ideológico-produtivo no Brasil, o agronegócio de maneira mais determinante a partir dos anos de 1990. Contexto no qual, o foco principal do Estado ético sob orientação do capital, está voltado para a "oferta de políticas educacionais voltadas para a classe trabalhadora camponesa, que contemplem os interesses relacionados à expropriação da terra e à consequente proletarização dos agricultores" (RIBEIRO 2012, p. 297).

Entretanto, este cenário não se dá sem resistências, sem um processo de disputa que, como indica Gramsci, ocorre no cerne da própria estrutura do Estado Ampliado. Sobre o processo de disputa por hegemonia, Mendonça indica que,

[...] a pré-condição para a transformação social e do Estado nas sociedades capitalistas é, segundo Gramsci, a multiplicação dos aparelhos de hegemonia da sociedade civil, ou seja, das visões de mundo e/ou vontades coletivas organizadas - que disputam entre sim, o tempo todo, a manutenção de um projeto hegemônico ou a imposição de outro que lhe seja contrário (contra-hegemônico), em busca de uma nova hegemonia (MENDONÇA, 2018, p. 14).

Neste sentido, observa-se no mesmo cenário histórico de avanço do capitalismo agrário sob a orientação neoliberal, o fortalecimento da atuação de movimentos sociais vinculados às lutas dos trabalhadores camponeses e sua articulação em torno do debate e elaboração de um projeto de educação da classe trabalhadora camponesa (e não para a): a Educação do Campo. Sendo fundado na década de 1990 o Movimento Por Uma Educação do Campo.

Este Movimento é instituído em torno da reflexão coletiva sobre as condições educacionais do campo e questão agrária, sendo discutidas em eventos regionais que

9 Omnilateral é um termo que vem do latim e cuja tradução literal significa "todos os lados ou dimensões". Essas dimensões envolvem a especificidade do ser humano, sua vida corpórea material e seu desenvolvimento intelectual, cultural, educacional, psicossocial, afetivo, estético e lúdico. Em síntese, educação omnilateral abrange a educação e a emancipação de todos os sentidos humanos (FRIGOTTO, 2012, p. 265). 
reuniram educadoras e educadores de áreas de reforma agrária em todo Brasil, cujo ápice se constituiu com a organização, no ano de 1997, do I Encontro Nacional das Educadoras e dos Educadores da Reforma Agrária, o I ENERA.

Neste processo de articulação e luta por um projeto popular de educação do campo, o PRONERA se apresenta enquanto uma importante conquista e I ENERA representa um marco da luta política. Expressão da decisiva atuação do MST na mobilização nacional em torno do questionamento das contradições históricas que se apresentam na realidade educacional campesina - em diálogo com a questão agrária e o projeto de reforma agrária - I ENERA contou com a participação de educadoras e educadores das áreas de assentamento do movimento social, instituições universitárias e científicas e organizações internacionais. Tendo definido em documento final, o Manifesto das Educadoras e dos Educadores da Reforma Agrária ao Povo Brasileiro, algumas das principais ideias-chave que irão orientar a construção do projeto da educação do campo:

No Brasil, chegamos a uma encruzilhada histórica. De um lado está o projeto neoliberal, que destrói a nação e aumenta a exclusão social. De outro lado, há a possibilidade de uma rebeldia organizada e da construção de um novo projeto. Como parte da classe trabalhadora de nosso país, precisamos tomar uma posição. Por essa razão, nos manifestamos

- Somos educadoras e educadores de crianças, jovens e adultos de acampamentos e assentamentos de todo Brasil, e colocamos o nosso trabalho a serviço da luta pela Reforma Agrária e das transformações sociais;

- Manifestamos nossa profunda indignação diante da miséria e das injustiças que estão destruindo nosso país, e compartilhamos o sonho da construção de um novo projeto de desenvolvimento para o Brasil, um projeto do povo brasileiro;

- Consideramos que acabar com o analfabetismo, além de um dever do Estado, é uma questão de honra. Por isso nos comprometemos com esse trabalho (MST, 2010, p. 132-133).

Identifica-se neste pequeno trecho do Manifesto, um caráter classista, a partir da definição da relação orgânica com um projeto popular de sociedade, desenvolvimento, campo e educação, articulado aos interesses da classe trabalhadora. Destaca-se, também, o questionamento do projeto neoliberal, mesmo que este não seja questionado em sua origem orgânica - a política do capital. Entretanto, neste documento é possível reconhecer a definição de um processo de disputa política de projeto, que reforça a acepção gramsciana que nos aponta para o 
Estado como expressão de governabilidade e de tensão entre classes e projetos políticos.

Apesar do reconhecimento da importância da Articulação Por Uma Educação do Campo, interessa demarcar que, o I ENERA contou com a parceria da Organização das Nações Unidas para a Educação, Ciência e Cultura (UNESCO). Mesma instituição que nos anos de 1990, esteve à frente na organização dos fóruns internacionais sobre educação, promovidos por organismos comprometidos com o fortalecimento e a ampliação da hegemonia do capital sobre a educação na América Latina. Dentre estes, Banco Mundial (BM), Organização Mundial do Comércio (OMC), Comissão Econômica para a América Latina (CEPAL), Oficina Regional de Educación para a América Latina y Caribe (OREALC).

Trata-se, desta forma, da atuação direta da UNESCO em duas frentes, que se apresentam em perspectivas antagônicas: a organização dos movimentos sociais camponeses no Brasil em torno da luta por um projeto popular de educação para a classe trabalhadora camponesa e a atuação direta nos eventos internacionais de organização do projeto do capital sob orientação neoliberal para educação na América Latina.

Desta feita, ao passo que se identifica contradições - que precisam ser desveladas numa perspectiva de estratégia e avaliação de processo - reconhece-se que o debate sobre a educação rural brasileira e materialidade da EJA em territórios rurais então instituído, trouxe grandes contribuições para a conquista de políticas educacionais articuladas aos interesses da classe trabalhadora camponesa e esteve assentado na crítica à precariedade da condição educacional dos espaços rurais. Para os quais, como afirma Caldart (2004, p. 57), são historicamente elaboradas e difundidas "políticas educacionais sob o paradigma rural que elegem o que the interessa como modelo econômico e cultura, sem incorporar as demandas apresentadas pela sociedade", bem como, a materialidade dos problemas sociais e educacionais que se apresentam nestes territórios.

Conforme a tarefa de retomar a preocupação da estratégia, Leher (2018, p. 61) reforça a necessidade imprescindível do "pensamento crítico retomar o diálogo sobre as primeiras experiências sistemáticas de educação popular", ou seja, de buscar a gênese dos projetos educacionais da classe trabalhadora para pensar horizontes. Neste sentido, destaca-se que, em sua origem, o projeto da educação do campo 
assume a dimensão de "pressão coletiva por políticas públicas mais abrangentes ou mesmo de embate entre diferentes lógicas de formulação e de implementação da política educacional brasileira" (CALDART, 2012, p. 261). Embora apresente, também, contradições que precisam ser desveladas e analisadas, o projeto originário apresenta como fundamento central, a emergência de que suas práticas reconheçam e busquem,

[...] trabalhar com a riqueza social e humana na diversidade de seus sujeitos: formas de trabalho, raízes e produções culturais, formas de luta, de resistência, de organização, de compreensão política, de modo de vida. Mas seu percurso assume a tensão de reafirmar, no diverso que é o patrimônio da humanidade que se almeja a unidade no confronto principal e na identidade da classe que objetiva superar, no campo e na cidade, as relações sociais capitalistas (CALDART, 2012, p. 262)

Trata-se portanto, em sua origem, de um projeto de luta pela hegemonia, que busca recuperar a lógica defendida por Lenin e Gramsci, de constituição de uma revolução cultural, isto é, de acesso das grandes massas operárias e camponesas a novos níveis de cultura - sendo os educadores considerados sujeitos fundamentais da formulação pedagógica e das transformações da escola e, a EJA apresentada como desafio de "instrumentalizar/armar os trabalhadores para que eles possam estabelecer ligações entre as várias áreas do conhecimento e sua relação com a luta de classes" (CALDART, 2012, p. 255).

Demarcando assim, como analisa Araújo (2018, p. 247), que a classe trabalhadora "não se porta como mera espectadora e que esta não é capaz de humanizar o capital, nem de criar uma nova sociabilidade onde seja possível articular harmoniosamente o mercado e a justiça social", já que a atuação do capital na construção da sociabilidade (cujo lucro é o ponto fulcral) tende, ao contrário, a expropriar direitos e conquistas - neste sentido, importa reforçar que a classe trabalhadora também constrói espaços de contra hegemonia e forma seus intelectuais orgânicos.

Destacando-se, a partir desta análise, um desafio histórico que se apresenta aos estudos, pesquisas e às estratégias de organização da classe trabalhadora: pensar as bases, os fundamentos, as categorias que se alinham a um projeto que se faça coerente à luta contra hegemônica, bem como, analisar as contradições internas e externas ao processo de construção do projeto popular. Reconhecendo a 
importância de valorização da história como processo e como método. Bem como, a atualidade das categorias fundantes do pensamento marxista - compreendidas em movimento - para o desvelamento do real constituído sob as tramas dos interesses do capital.

\section{Algumas considerações}

Encerra-se este texto demarcando que, diante das históricas contradições geradas pela exploração da classe trabalhadora pelo capital:

[...] nós temos que forjar um projeto político e estratégico para que os trabalhadores possam fazer luta de classes na educação à altura, com projetos objetivos, que tenham consistência teórica e metodológica, mas sobretudo, projetos que tenham o germe da perspectiva socialista (LEHER, 2018, p. 61).

Sendo essencial para o avanço estratégico - tanto no campo das pesquisas quanto da construção coletiva alternativas da classe trabalhadora à hegemonia do capital - sob a perspectiva do método materialista histórico-dialético, compreender que: partindo das categorias simples, perscrutando-as em relação com a totalidade das determinações, ou seja, das relações diversas que interferem na materialidade destas categorias, poderemos chegar ao concreto pensado, refletido, questionado como orienta Marx em sua Contribuição à Crítica da Economia Política (2008, p. 260 261).

Só então poderemos vislumbrar - com os pés fincados no chão da história e com o compromisso de desvelar tramas e contradições forjadas pelo capital - o fortalecimento dos projetos de enfrentamento, assumindo de maneira coerente e fundamentada a tarefa de elaboração e difusão de conhecimentos, comprometidos com a formação de intelectuais orgânicos da classe trabalhadora. Dando movimento ao projeto de Estado ético, ou de cultura, articulado aos interesses da classe que produz valor e que é historicamente expropriada de suas condições de vida, trabalho e dignidade.

A EJA e a educação rural se apresentam, assim, como territórios de disputa, cuja importância ultrapassa os limites das pesquisas, que, por sua vez, apresentam a emergente necessidade de serem refletidas e constituídas à luz do real e em perspectiva material. Sendo, para tanto, necessária a superação das redomas impostas à construção acadêmica do conhecimento, compreendendo-nos enquanto 
classe trabalhadora, enquanto pesquisadores intelectuais orgânicos, mulheres e homens coletivos, capazes de criticar a própria concepção de mundo e de construir conhecimento em orgânica relação com a realidade, como orienta Gramsci.

A investigação da realidade da EJA e da Educação Rural no Brasil, aponta para uma histórica precarização das políticas educacionais voltadas para a educação da classe trabalhadora camponesa. Que, por sua vez, encontra-se aliada às condições de sociabilidade do capital, materializadas tanto através da negação de direitos e acesso à educação escolar - num processo de expropriação cultural - quanto da oferta de políticas educacionais limitadas aos interesses estreitos do mercado, a partir dos quais a classe trabalhadora é tratada como meio de produção.

Entretanto, partindo de uma compreensão dialética da história, reafirma-se que as contradições advindas do projeto de sociabilidade capitalista podem ser superadas por meio da ação humana, sendo cultura e educação elementos fundamentais para o processo de resistência e luta por hegemonia. Neste sentido, reconhece-se a luta pela Educação do Campo, articulada à luta pela Reforma Agrária como um importante instrumento de resistência popular e conquista de veredas para um projeto social revolucionário, na medida em que, a sua construção permaneça atrelada ao projeto de revolucionário, comprometido questionamento radical da realidade e não ceda às imposições interesseiras do capital, a seus fundamentos e projetos.

Interessa demarcar, também, que as políticas de Educação Rural e EJA no Brasil - enquanto questões de classe - são caracterizadas por uma lógica que indica a condição de oferta residual, frágil, descontínua, sem que os problemas e contradições presentes em sua materialidade, alcancem as necessidades educacionais requeridas pelo longo processo de negação de educação de qualidade à classe trabalhadora camponesa. Tratam-se, portanto, de problemas amplos, que se encontram envoltos em uma totalidade historicamente contraditória.

Portanto, sob a perspectiva do materialismo histórico-dialético - e, considerando a atual conjuntura brasileira, onde 0 incessante processo de reconfiguração do capitalismo se alia ao fortalecimento da extrema direita reconhecemos que o tempo pede que em nossos estudos, pesquisas e organizações sociais, recortes a-históricos, fragmentações e reducionismos, narrativas sem totalidade, gabinetes sem vida e movimento sejam abandonados. E que, partindo de uma perspectiva de totalidade, o vínculo das nossas pesquisas com as necessidades 
da classe trabalhadora, sejam o seu principal tom. Pois, o fantasma que assombra nosso "derredor" histórico nos quer controlados. É imperativo resistir e produzir estudos e pesquisas com fundamento, compromisso histórico e unidade.

\section{Referências}

ARAÚJO, Lenilde de Alencar. A participação da Fundação Vale na educação do Maranhão. In: STAUFFER, Analeila de Barros et al. Hegemonia burguesa da educação pública: problematizações no curso TEMS (EPSJV/Pronera). Rio de Janeiro: EPSJV, 2018.

BRUNO, Regina. Desigualdade, agronegócio e agricultura familiar no Brasil. Disponível <http://www.agr.feis.unesp.br/jj311200a.htm> Acesso em 10.01.2019.

CALDART, Roseli Salete. Pedagogia do Movimento Sem Terra. São Paulo: Expressão Popular, 2004.

CALDART, (et. al) (Orgs.). Dicionário da educação do campo. São Paulo: Expressão Popular, 2012.

CIAVATTA, Maria. O trabalho docente e os caminhos do conhecimento: historicidade da educação profissional. Rio de Janeiro: Lamparina, 2015.

FONTES, Virgínia. Reflexões im-pertinentes: história e capitalismo contemporâneo. Rio de Janeiro: Bom Texto, 2005.

FONTES, Virgínia. O núcleo central do governo Bolsonaro: o proto-fascismo. Disponível <https://esquerdaonline.com.br/2019/01/08/o-nucleo-central-do-governobolsonaro-o-proto-fascismo/> Acesso em 10.02.2019.

FRIGOTTO, Gaudêncio. A produtividade da escola improdutiva. São Paulo: Cortez, 2010.

FRIGOTTO, Gaudêncio. Educação omnilateral. In: CALDART, (et. al) (Orgs.). Dicionário da educação do campo. São Paulo: Expressão Popular, 2012.

GRAMSCI, Antonio. Cadernos do cárcere. vol. 3. Rio de Janeiro: Civilização Brasileira, 2017.

. Cadernos do cárcere. vol. 4. Rio de Janeiro: Civilização Brasileira, 2015.

. O leitor de Gramsci: escritos escolhidos 1916-1935/Carlos Nelson Coutinho, organizador. Rio de Janeiro: Civilização Brasileira, 2011.

. Cadernos do cárcere. vol. 1. Rio de Janeiro: Civilização Brasileira, 1999. 
1987.

. Concepção dialética da história. Rio de Janeiro: Civilização Brasileira,

GRUPPI, Luciano. Tudo começou com Maquiavel: as concepções de Estado em Marx, Engels, Lênin e Gramsci. Porto Alegre: L\&PM, 1980.

INEP/MEC. Mapa do analfabetismo no Brasil. Disponível < http://portal.inep.gov.br/documents/186968/485745/Mapa+do+analfabetismo+no+Bra sil/a53ac9ee-c0c0-4727-b216-035c65c45e1b?version=1.3> Acesso em 03.dez.2018.

KOSIK, Karel. Dialética do concreto. Rio de Janeiro: Paz e Terra, 2011.

LAMOSA, Rodrigo de Azevedo Cruz. Estado, classes sociais e educação no Brasil: uma análise crítica da hegemonia da associação brasileira do agronegócio. Programa de Pós-Graduação em Educação da Universidade Federal do Rio de Janeiro (Doutorado em Educação). Rio de Janeiro/UFRJ: 2014.

LEHER, Roberto. Marxismo, educação e politecnia. In: STAUFFER, Analeila de Barros et al. Hegemonia burguesa da educação pública: problematizações no curso TEMS (EPSJV/Pronera). Rio de Janeiro: EPSJV, 2018.

LENIN, V. I. O Estado e a revolução. São Paulo: Expressão Popular, 2010.

LUKÁCS, György. Ontologia do ser social: os princípios ontológicos fundamentais de Marx. São Paulo: Livraria Editora Ciências Humanas, 1979.

MARX, Karl; ENGELS, Friedrich. Manifesto do partido comunista. São Paulo: Boitempo, 2010.

A ideologia alemã. São Paulo: Martins Fontes, 2007.

MARX, Karl. O Capital - Livro I. São Paulo: Boitempo, 2017.

Popular, 2008.

Contribuição à crítica da economia política. São Paulo: Expressão

MATTOS, Marcelo Badaró. E. P. Thompson e a tradição de crítica ativa do materialismo histórico. Rio de Janeiro: Editora UFRJ, 2012.

MENDONÇA, Sonia Regina de. Estado e educação rural do Brasil: alguns escritos. Niterói/Rio de Janeiro: Vício de Leitura/FAPERJ, 2007.

MENDONÇA, Sonia Regina de. Pesquisando com Gramsci: sugestões metodológicas. In: MENDONÇA, Sônia Regina; LAMOSA. Rodrigo. Gramsci e a pesquisa histórica. Curitiba: Appris, 2018.

MÉSZÁROS, I. O desafio e o fardo do tempo histórico. São Paulo: Boitempo, 2007. MST. Manifesto das educadoras e dos educadores da reforma agrária ao povo brasileiro. In: GENTILLI, Pablo; TRISTAN, McCowan (Orgs.). Reinventar a escola pública: política educacional para um novo Brasil. Petrópolis: Vozes, 2010. 
RIBEIRO, Marlene. Educação rural. In: CALDART, (et. al) (Orgs.). Dicionário da educação do campo. São Paulo: Expressão Popular, 2012.

RUMMERT, Sonia Maria. Educação e identidade dos trabalhadores: as concepções do capital e do trabalho. São Paulo: Xamã, 2000.

RUMMERT, Sonia Maria. Educar e qualificar: caminhos e descaminhos da educação de jovens e adultos trabalhadores. Perspectiva. Florianópolis, v. 31, n. 2, maio/ago. 2013.

RUMMERT, Sonia Maria. Novos projetos e velhas disputas no cenário da educação da classe trabalhadora brasileira. In: BOMFIM, Maria Inês; RUMMERT, Sonia Maria (Orgs.). Educação de jovens e adultos da classe trabalhadora brasileira: "novos" projetos e antigas disputas. Curitiba: CRV, 2017.

THOMPSON, E. P. A formação da classe operária inglesa: árvore da liberdade. Rio de Janeiro/São Paulo: Paz e Terra, 2018. 